\title{
CARLOS ESPARTACO
}

\section{AVATARES DE LA CRÍTICA}

Discurso: Nivel de la obra que escapa a las reglas narrativas y surge de reglas de argumentación, de retórica...

No he de ocultar, ni siquiera he pensado en persuadir, o mínimamente sugerir, que el paradigma del título inaugural de esta intervención que trata de llamar la atención sobre el sistema que otorga validez a la enunciación, se basa fundamentalmente, como diría Filiberto Menna cuando intentaba otorgarle su voto de confianza al "Proyecto Moderno del Arte" equiparando la entidad del sujeto con la vida cotidiana, en descubrir las referencias que se ocultan detrás de la disyunción que parece presidir las consonancias del nombre que da su sentido a la operación escrita.

De acuerdo con Menna, la connivencia entre el sujeto y la vida cotidiana determinaría que el espacio estético se transforme en el receptáculo o en el lugar privilegiado para el movimiento del individuo hacia una plena realización de sí mismo. El modelo está dado por la actividad artística recuperada como procedimiento que encuentra en su indagación, motivaciones que se continúan en metas, asumiendo por esta razón, el significado de un trabajo donde las facultades creativas del sujeto encuentran libre y pleno despliegue. "La condición necesaria, pero no automáticamente suficiente, es 
que el arte supere la distancia de la obra terminada, transformandose en 'esteticidad difusa' y por el trámite de esta última, en un ejercicio diferente de la vida cotidiana" (Menna).

Pero no debemos olvidar que estamos en una época donde la problemática del arte no es ajena a ningún componente del circuito artístico. De este modo, el artista, el crítico, el teórico y el historiador del arte, ingresan en el círculo de la serpiente que se muerde la cola, de la reiteración del arte y su historia sin descartar el conjunto de la problemática cultural moderna y su consecuente contemporaneidad.

Si nos situamos en el siglo XX, de inmediato constatamos una proliferación de escuelas y movimientos que arrastran lo que en el siglo anterior fue designado como lo "Moderno" cada vez más grande; y esta convención acumulativa, frente a la cual el crítico yel historiador de hoy se sienten de alguna manera desbordados, reproduce fielmente las divisiones y los antagonismos que manifiestan las diversas vanguardias: el crítico de arte transformado en especialista, algunas veces en promotor exclusivo de artistas que reúne bajo cualquiera de las denominaciones de época con que se designan las tendencias más puntuales. A su vez el historiador establece una cronología, un recorrido y una lógica de la evolución de las obras, que supone la elección exclusiva de ciertosmovimientos artisticos y el rechazo o la ignorancia de otros. No podemos dejar de observar que el tiempo de saturación de las formas, ideas y estilos, que produce el hecho acumulativo de las vanguardias, niega toda posibilidad de acordar el menor crédito a esa actitud crítica y a la historia.

Entonces, ¿qué camino se puede elegir en la actualidad frente a la pretendida modernidad, que a posteriori de un siglo reina confusamente en el arte? Más allá del siglo XIX, ¿cuáles son las acumulaciones de tendencias y objetos "modernistas"que ocupan las dos terceras partes de nuestro casi extinto siglo XX? Seamos puntuales y detengamos nuestros vacilantes pasos - los vasos comunicantes se rompieron en el laboratorio de las especulaciones y la duplicidad de los sentidos -, exactamente ahí, descubrimos que un conjunto considerable de obras, cuyo carácter aparentemente menor en cuanto a actualidad, puede denotar cierta pérdida de interés pos las mismas. Si al contrario optamos por el conjunto de las manifestaciones artísticas modernas, abarcativas del siglo $\mathrm{XIX}$ y lo que va del XX, que encuentran hoy su lugar en los diferentes centros culturales o Museos de Arte Moderno y Contemporáneo, quedamos impresionados por la vitalidad de las expresiones artisticas de nuestra época y la cantidad de energía puesta en obra. 
Por lo tanto, pareciera que en el medio artístico por excelencia, en base a especialistas, críticos, historiadores, conservadores de museos, dealers y amateurs, no se tendría otra mira que la especulaçión día tras día. La cosa no es tan simple y podemos demandarnos, si es posible tomarlo en consideración, la vitalidad del conjunto de los movimientos artísticos modernos y contemporáneos, sin perdernos en los meandros anecdóticos de los gropúsculos que los componen. Cuestionamiento imposible de realizar sin que aparezca la obligación que a esta altura de los tiempos debemos subrayar, y tanto como fuera posible explicitar, en lo referente a la dimisión y quiebra de la actitud del crítico y el historiador del arte.

Sí en rigor se puede pensar que el crítico por su función está justificado en la medida de su actualización puntual de la información artística; siempre y cuando en ese rol se cuide de emitir todo juicio prospectivo capaz de convencernos, si antes no demuestra la existencia de información objetiva, no siendo posible restarle operatividad a la economía de los presupuestos ideológicos que motivan al historiador del arte, que por otra parte, frecuentemente es el que motoriza implícitamente los del crítico.

Por otra parte, si más allá de los fulgores de la acumulación de formas y objetos modernistas que han sido legados, nos colocamos, entre paréntesis, frente a la organización y función de los dircursos que han respondido y responden a la puesta en acto parcial y global del conjunto de los objetos artísticos, constatamos que en sus actitudes aparentemente diferentes, la posición de los historiadores del arte moderno surge siempre de presupuestos filosóficos que manifiestan idéntico origen. En efecto, al considerar el conjunto del recorrido cultural del que somos herederos, llegamos a la conclusión provisoria de que la relación del arte con el discurso acompañante solamente ha sufrido mínimas transformaciones.

En lo concerniente al siglo XX, la relación del arte con el discurso sobre el arte se constituye esencialmente en base a dos formas de organización: teológica y filosófica. De hecho, parece posible considerar el orden que suponen las series propuestas por Vasari como formalmente comprometidas en un tipo de apreciación teológica del fenómeno artístico en la medida en que "las historias" se consumen en sus "raptos" propios, que excesivamente veloces no pueden fundar ningún concepto de historia.

La espera se prolongará hasta el siglo XVIII, siglo que habilita la conjunción Winckleman-Kant para pasar de una historia conceptualizada a 
partir de un principio de evolución, desarrollo biológico sobre el modelo vegetal o el modelo humano de las etapas de la vida, a otra fundada en la filosofia de la naturaleza que va a intentar anclar sus bases en el prestigio sobredeterminado del genio del artista.

Esta racionalización y teorización de la historia del arte no se detiene ahí, al contrario, a partir de ese momento y en todas las formas que ha podido adoptar más tarde, la metafísica (Kant) sometiendo la moral a la psicología, argucias de la naturaleza, evacúa lo imponderable de la creación artística poniendo de esta manera al sujeto creador en continuo estado de crisis (crisis que tomaron rápidamente el nombre de "crisis psicológicas" sin que se encuentre reducidoel problemaque manifiestan). Entonces, $i$ noes sorprendente que soñemos constatar que el bello ordenamiento de los sistemas y de las filosofias de la historia de loscuales somos herederos, se encuentren acompañadas de su puesta en escena en la segunda mitad del siglo XVIII, a partir del Romanticismo, de tal confusión dramática en el dominio artístico? Debemos aclarar que no sólo en el poeta Schiller y el escritor Schlegel va a manifestarse esa sumisión del arte a la filosofia. El exceso, parece una respuesta a las agitaciones del siglo y al cuestionamiento de la introducción de una moral no más sometida a la teología. La obra de Kant inscribe sus marcar tanto en los escritores como en los pintores.

El anclaje, la invención de una historia muy próxima a la que pensamos hoy, no está ligado únicamente a la curiosidad o al snobismo de alguns escritores y artistas. En rigor, encuentra su lugar en el orden de las contradicciones y los desarrollos del pensamiento científico y técnico, y con un sistema y pensamiento teológico del mundo. Contradicciones tales como el desorden, la revolución y las instituciones acompañantes, reclaman y se empeñan en fundar un nuevo orden. Con toda esta evidencia, es en este contexto general que escritores y pintores se encuentran enfrentados al sistema, y más inmediatamente al sistema Kantiano, tal como este último funda su ley basándose en un debate moral y psicológico.

El ordenamiento y la posterior ubicación de las sumisiones a la racionalidad filosófica, producirán todo lo que conocemos del arte del siglo XIX y XX. El escritor, intentando investir los imponderables del gesto y el lenguage poético, poniendo a punto una nueva forma literaria, compromete la lengua en la confusión de los "dramas" psicológicos: la novela. El pintor a lo largo del siglo XIX lanzado al abordaje de la sistematización de la naturaleza, representa la ideas kantianas en medio de figuras simbólicas, logrando 
inscripciones nomenos simbólicas: Romanticismo, Realismo Impresionismo.

La dimensión de la obra se encuentra ligada a lo que ella misma hace surgir absurdamente en la lógica del sistema o, mejor dicho, a la cualidad del síntoma de adaptación que manifiesta. A riesgo de no encontrar otro lugar, el arte moderno, progresivamente se dará como función representar el desnivel, según una lógica selectiva y rigurosamente establecida por el orden del sistema; posición actualmente dominante, la manifestación marginal, secundaria, es casi la marca acultural de los fracasos del sistema, de donde surge la propensión a confundir cada vez más, la producción plástica de los enfermos mentales y la de los artistas plásticos.

Ahora bien, si queremos ver más claramente, no nos detengamos en este tipo de análisis, en este momento debemos subrayar que la dimisión del crítico y la del historiador se producen por el hecho de que dejaron de interrogar aquello que en la historia ordena la función y la ubicación del arte y el artista, a saber: la psicología, en tanto que ella pesa a la moral.

En efecto, encontramos que de crisis en crisis, la exposición artística y psicoanalitica de los excesos psiquiátricos y la consecuente generalización de la miseria que produce el "sistema", determinan el armado de los subterfugios: la psicología. Se comprende muy bien que a través de la obra de Freud, el descubrimiento del inconsciente da otra dimensión, no psicológica, al caráter lúdico del arte, y al evidenciar el malestar de la civilización entre desplazamientos y condensaciones, Freud produce una ruptura con la integridad del sistema y la historia.

En resumen, contrariamente a lo que algunos parecen pensar, con la teoría freudiana del lenguaje (Lacan) no entramos en la era de la psicología, sino que salimos de ella. $Y$ desde entonces, la posibilidad de pensar aquello que en el interior del "sistema", de la historia, de acuerdo a lo que acontece con la tautología de las crisis y retornos, donde las relaciones representativas se anulan reciprocamente en cuanto no están, como diría Wittgestein, "en ninguna representación representativa con la realidad", y llegan a impedir no exáctamente la sobredeterminación, sino lo sobredeterminante metafísico, moral y filosófico.

Desde ese momento, Jas múltiples formas del arte moderno se ordenan fuera de la cronología o el recorrido sistemático de la historia, introduciéndose sintomáticamente en lo manifiesto de la represión, que las fija 
relativamente sobre el objeto que pretenden trascender. Pensava desde este punto de vista la acumulación progresiva de acuerdo a un ritmo cada vez más precipitado a medida que se aproxima a nosotros. Las múltiples escuelas y reagrupamientos del arte moderno tienden a señalarnos lo irrisorio de toda apreciación en lo referente a sus historias.

Por otra parte, aquello que se expone en su diversidad, si es tomado en su conjunto, no configura, en principio, la crítica implícita de cualquier posición que históricamente fundaría la cronología; la repetición y represiónque supone, no persiguen como primera instancia suspender el tiempo y reiterar por condensación o desplazamiento la fijación traumática. En este sentido e insistiendo una vez más en su diversidad, el conjunto de los movimientos del arte moderno parece seguir determinando el juego complejo de una siempre contemporánea resistencia al sistema; la historia de una evolución formal o ideológica que algunos intentan probar de manera fortuita.

Esta forma de resistencia ha tomado en el curso del último decenio tal desarrollo que es imposible ignorarla. La especie de contemporaneidad implicita que indican por un acercamiento cada vez más estrecho en el tiempo, es decir la sucesión y acumulación de los movimientos del arte moderno, deviene hoy completamente explícita con la coexistencia simultánea, a menudo en el mismo país y a veces en un mismo artista; una pluralidad de actitudes y estilos. Lo que de entrada puede ser observado, en ciertos artistas conceptuales, como rechazo relativamente sociológico de la originalidad y cualidad estética de la obra de arte, ha sido aún más sintomático que original, en lo que esos artistas reiteran a través de una puesta en escena formalmente anecdótica de la "situación del arte" según esquemas próximos al discurso periodistico; la exposición de datos de la crisis en la que la totalidad de los siglos XIX y XX dan su testimonio. Esta actitud admitida como nueva forma de vanguardia, de la que muy pocos ejemplos presentan un real interés, obtiene cierto éxito en la medida en que jugando con su propio gesto de aparente radicalización, arriba a su turno frentre a la ambigüedadde la actitud "marchand" a que se presta, a justificar por adicción a una nueva forma vanguardista, el sistema cronológico de lo que se ha convenido en llamar la historia del arte moderno.

- La situación contemporánea escapa totalmente a esta especie de malentendido en lo que respecta a su pretendida inscripción en contra de la corriente del juego. Sin embargo, es convencional, de huída hacia adelante, lo que caracteriza las posiciones de todos los movimientos "vanguardistas". La 
acumulación de movimientos, maneras, manías, actitudes y estilos que encontramos durante la década de los 80 , tanto en Italia como en Berlín, París, Nueva York y los reflejos en la periferia latinoamericana - Buenos Aires lentamente incorpora casi todo lo que sucede en el mundo internacional del arte compromete un proceso menos novedoso que de búsqueda de la diferencia, y en tanto que tal, desorganiza la especulación (marchand, crítica e histórica) de la tradición de las vanguardistas y los modernismos.

Si en un primer momento, se busca comprender y analizar lo que significa esta coexistencia acumulativa de movimientos, actitudes, maneras y estilos, simultáneamente no podemos ser impactados por el carácter de la función histórica que cumplen. El conjunto de la producción contemporánea no parece, en efecto, de ninguna manera surgir del leitmotiv' de los vanguardismos, con lo que esto supone como filosofia de la historia, o de alguna proyección explícita por adelantada que estuviera, sino de la contemporaneidad en cuanto a asumir su situación propriamente dicha; y asumiendo esa conquista relevar todo lo que pueda tener de contradictoria y compleja en la relación que debe mantener con la historia explícitamente dominante, aunque implícitamente nula y abismada.

Estamos de acuerdo en que los años ' 80 introdujeron en aparencia otra proliferación: la del arte joven. Si los consideramos independientemente o en su conjutno, podriamos decir que los jóvenes artistas contemporáneos, aciertan en función de ese modelo de resistencia al "sistema" y los niveles característicos sintomáticos que supone, cuando se comprometen y retoman el conjunto problemático de la idea de lógica - lo que nos determina a pensar nuevamente la "modernidad" como la repetición de una misma crisis - y contemporaneizando y actualizando la cada vez más grande inadecuación de la masa global de encuentros y proposiciones formales e ideológicas comprometidas en ese vasto juego.

Las obras que presentaban frecuentemente resisten y explicitan su resistencia a las semejanzas con la modernidad desbaratando la convención que impone hoy al artista simular la producción de lo nuevo como si lo "viejonuevo", la historia moderna, hubiese sucedido. A su manera, parece que dijeran en la actualidad, mejor dicho se pronunciaran, por ese no lugar del arte moderno, tal como este último interroga todo sistema y se descubre como problemática específica al tratamiento de la fijación traumática, que operando "históricamente" la represión, transmite como tarea a su actualización el cuestionamiento de su repetición y reiteración por condensación y 
desplazamiento.

Algunos artistas llegan hasta retomar el problema en el punto mismo de su anudamiento, y confrontan ese extenso presente sinuoso del arte moderno, incluso sus confusiones formales a la coherencia teológica de las obras del pasado, marcando en el lugar una nueva apropiación de los datos suceptibles de aclarar la aproximación del difícil problema de la historia del arte.

Otros invisten nuevamente y actualizan los aspectos más significativamente sujetados al ordenamiento y resolución de las crisis que historizan, y no es para asombrarnos cuando de las citaciones mayores a Picasso y Matisse, los jóvenes pintores pasan a evocar datos de la "Action Painting" y el "Expresionismo Abstracto Norteamericano", el "Expresionismo Alemán"y la "Escuela de París". Esta revaluación del conjunto de problemas que introduce a la "modernidad" es sólo el comienzo de una anunciación; pero ya podemos presumir los indicios de un enfrentamiento con las antiguas metas del arte y de la historia. Como dice Pleynet, "la interpretación se apoya en suposiciones, pero no hay que descuidar lo que positivamente se designa ahora como "Eclecticismo", en el sentido estricto de la palabra, y conmueve las fijaciones, las costumbres, las convenciones y los modos de ser y de pensar establecidos por el sistema de la historia del arte moderno, que un día u otro el crítico y el historiador deberán entender que significa: no confundir Historia y Teoría, Teoría y Sistema.

Deste otro punto de vista, la ideología estética moderna enfrentada con la perspectiva política y tecnológica, tiene un sentido positivo y negativo al mismo tiempo. Aquí también se trata de cuestiones muy actuales, sobre todo en una fase histórica como la que estamos viviendo, donde los cambios sociales aparecen bastante "difusos" y profundos para justificar la hipótesis de un verdadero traspaso de época, de un pasaje de la "modernidad" a una "condición postmoderna".

En ese pasaje, temas y figuras del arte moderno habrian perdido definitivamente su incidencia concreta, rebelándose como residuos de un pensamiento humanistico y que la condición actual relegaría definitivamente hacia una nueva superestructura. Pero, las cosas no son tan simples, debido a que cada vez más frecuentemente se hacen propuestas de una revisita crítica de la modernidad con la finalidad de individualizar, en lo interno de ella, los valores que puedan ser considerados aún operantes en la configuración de nuestro presente-futuro. 
CARLOS ESPARTACO - Crítico, teórico e ensaista. Principais publicações: Encuentro (poemas), La Persistencia (nouvelle), El estupor del arte, Arte y discurso. Coloborador del diario Clarin. 